\title{
Neuronal Morphology Analysis
}

Désirée R. M. Seib*, Ana Martin-Villalba*

Molecular Neurobiology, German Cancer Research Center (DKFZ), Heidelberg, Germany *For correspondence: seibdesiree@gmail.com; a.martin-villalba@dkfz-heidelberg.de

[Abstract] This protocol describes how to visualize neuronal morphology and how to determine neuronal complexity of immature and mature hippocampal neurons in the mouse in vivo including tissue preparation, staining of brain sections and confocal cell analysis.

\section{Materials and Reagents}

1. Mice

2. $\quad 0.9 \%$ sterile Sodium chloride $(\mathrm{NaCl})$ (Fresenius Kabi)

3. Ketamine hydrochloride (Ketavet, $100 \mathrm{mg} / \mathrm{ml}$ ) (Pfizer)

4. Xylazine hydrochloride (Rompun, $20 \mathrm{mg} / \mathrm{ml}$ Xylazine) (Bayer)

5. 4\% Paraformaldehyde in phosphate buffer (4\% Roti-Histofix) (Roth, catalog number: P087.1)

6. Hank's balanced salt solution (HBSS) (Life Technologies, Invitrogen ${ }^{\mathrm{TM}}$, catalog number: 14170-138)

7. Sodium chloride ( $\mathrm{NaCl}$ ) (Sigma-Aldrich, catalog number: 31434)

8. Sodium phosphate dibasic heptahydrate $\left(\mathrm{Na}_{2} \mathrm{HPO}_{4} \cdot 7 \mathrm{H}_{2} \mathrm{O}\right)$ (Sigma-Aldrich, catalog number: S9390)

9. Sodium phosphate monobasic monohydrate $\left(\mathrm{NaH}_{2} \mathrm{PO}_{4} \cdot \mathrm{H}_{2} \mathrm{O}\right)$ (Roth, catalog number: K300.2)

10. Potassium chloride ( $\mathrm{KCl})$ (AppliChem $\mathrm{GmbH}$, catalog number: A3582)

11. Potassium phosphate monobasic $\left(\mathrm{KH}_{2} \mathrm{PO}_{4}\right)$ (Gerbu, catalog number: 2018)

12. Sodium azide (Sigma-Aldrich, catalog number : S2002)

13. Hydrochloric acid ( $\mathrm{HCl}, 37 \%)$ (Sigma-Aldrich, catalog number: 30721)

14. Trizma base (Sigma-Aldrich, catalog number: T1503)

15. Horse serum (Biochrom, catalog number: S9135)

16. Triton X-100 (Sigma-Aldrich, catalog number: X-100)

17. Chicken anti-GFP antibody (Aves, catalog number: GFP-1020)

18. Goat anti-Doublecortin antibody (DCX, C18) (Santa Cruz, catalog number: sc-8066)

19. Mouse anti-NeuN antibody (EMD Millipore, catalog number: MAB377)

20. Donkey anti-chicken DyLight488 antibody (Dianova, catalog number: 703-485-155) 
21. Donkey anti-goat Alexa 647 antibody (Dianova, catalog number: 705-605-147)

22. Donkey anti-mouse Alexa 546 antibody (Life Technologies, Invitrogen ${ }^{\mathrm{TM}}$, catalog number: A10036)

23. Hoechst (33342) (Biotrend, catalog number: 40047)

24. Gelatine to coat glass slides (Sigma-Aldrich, catalog number: G7041)

25. Chromium (III) potassium sulfate dodecahydrate (Sigma-Aldrich, catalog number: 60152)

26. Bromothymol Blue sodium salt (Sigma-Aldrich, catalog number: 114421)

27. FD Rapid GolgiStain ${ }^{\text {TM }}$ Kit (FD NeuroTechnologies, catalog number: PK401)

28. Millipore water

29. Ethanol (Sigma-Aldrich, catalog number: 459844)

30. Xylene (Sigma-Aldrich, catalog number: 33817)

31. Eukitt (Fluka, catalog number: 03989)

32. Agarose (AppliChem $\mathrm{GmbH}$, catalog number: A8963)

33. Phosphate buffer saline (PBS) (20x) (see Recipes)

34. TBS (10x) (see Recipes)

35. TBS++ (see Recipes)

36. $0.1 \mathrm{M}$ Phosphate buffer (see Recipes)

37. Gelatine to coat glass slides (see Recipes)

38. Mowiol (Merck/Calbiochem, catalog number: 475904) (see Recipes)

\section{Equipment}

1. Syringe ( $1 \mathrm{ml}$ syringe $27 \mathrm{G}$ for i.p. injections)

2. $0.5 \mathrm{ml}$ Eppendorf Safelock tubes

3. $15 \mathrm{ml}$ and $50 \mathrm{ml}$ Falcon tubes

4. Micro dissecting scissors

5. Forceps

6. Leica VT1200 Vibratome

7. Brush to transfer slices

8. Netwell carriers and plates (Corning Inc., catalog numbers: 3477 and 3520)

9. Rocking platform

10. Tube roller mixer

11. Hot plate stirrer

12. Staining containers

13. Microscope glass slides

14. Cover slips

15. Confocal microscope 
16. Centrifuge

\section{Software}

1. Amira Filament Editor Analysis (Visage Imaging) or other neuron morphology analysis software

\section{Procedure}

A. Tissue preparation

1. Transcardial perfusion

Animals are anesthetized with an overdose of Rompun (14 mg/kg bodyweight) and Ketavet (100 mg/kg bodyweight) in $0.9 \% \mathrm{NaCl}$.

Mice are transcardially perfused with $30 \mathrm{ml}$ HBSS followed by $10 \mathrm{ml}$ of $4 \%$ paraformaldehyde (PFA) dissolved in $0.1 \mathrm{M}$ phosphate buffer $\mathrm{pH}$ 7. For transcardial perfusion the thorax cavity is opened, and the right auricle cut with a scissor to allow bleeding. A butterfly cannula is introduced in the left ventricle and mice are perfused with $30 \mathrm{ml}$ HBSS followed by fixation with $10 \mathrm{ml}$ 4\% PFA.

Brains are removed and post-fixed overnight in $10 \mathrm{ml}$ 4\% PFA in $0.1 \mathrm{M}$ phosphate buffer $\mathrm{pH} 7$ in a $15 \mathrm{ml}$ Falcon tube on a tube roller mixer at $4{ }^{\circ} \mathrm{C}$.

Tissue is washed twice with PBS and may be stored in PBS with $0.01 \%$ sodium azide for up to a year.

B. Neuronal morphology analysis of immature dentate gyrus neurons

1. Vibratome cutting

a. For coronal vibratome sections (see Figure 1), the cerebellum is cut, removed and the brain glued upright with the cutting site using superglue onto the holder plate of the vibratome. Coronal sections may have a thickness of $50 \mu \mathrm{m}$ or $100 \mu \mathrm{m}$.

Note: The NeuN antibody does not very well penetrate $100 \mu \mathrm{m}$ thick sections. If you have to use $100 \mu \mathrm{m}$ thick sections primary antibody incubation should be $72 \mathrm{~h}$.

b. For sagittal sections (see Figure 1 ) brains are embedded in $2 \%$ agarose in PBS. The brain is then glued in a solid gel block on the lateral side to the holder plate. Sagittal sections are cut $100 \mu \mathrm{m}$ thick. Agarose can be removed from the slices during cutting or may be kept during the staining process in order to stabilize the tissue (especially olfactory bulbs).

c. Sections can be stored in PBS with $0.01 \%$ sodium azide at $4{ }^{\circ} \mathrm{C}$. Tissue might be used for up to one year after perfusion. 
Coronal brain sections
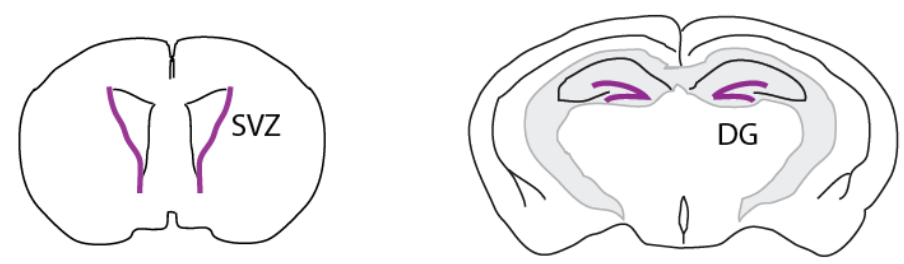

Sagittal brain sections

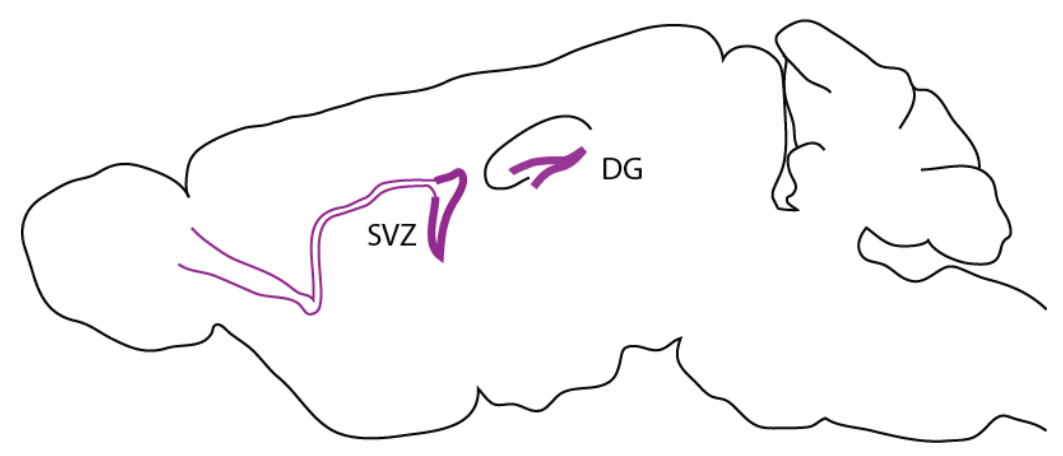

Figure 1. Overview of neurogenic niches in coronal and sagittal brain sections (SVZ: subventricular zone; DG: dentate gyrus)

2. Immunofluorescence staining

a. For each mouse, 4 brain slices (50 or $100 \mu \mathrm{m}$ thick, $250 \mu \mathrm{m}$ or $300 \mu \mathrm{m}$ apart, respectively) are stained. Brain sections are placed in net carriers in 12 well plates (2 slices per well) filled with $4 \mathrm{ml} 0.1 \mathrm{M}$ Tris Buffer $\mathrm{pH} 7.4$ supplemented with $8 \% \mathrm{NaCl}$ (TBS). The sections are washed three times in TBS each 15 min at RT on a rocking platform (50 rpm).

b. Blocking of unspecific antibody binding is performed by incubating sections for $1 \mathrm{~h} \mathrm{in}$ TBS++ at RT.

C. Sections are transferred to $0.5 \mathrm{ml}$ Eppendorf Safelock tubes (2 sections per tube) containing $200 \mu \mathrm{l} \mathrm{TBS}++$ and the diluted primary antibodies, and incubated at $4{ }^{\circ} \mathrm{C}$ for 24-72 $\mathrm{h}$. For this 12 tubes are put in a $50 \mathrm{ml}$ Falcon and rotated at $4{ }^{\circ} \mathrm{C}$ on a tube roller mixer.

i. For staining of GFP/YFP of either genetically or retrovirally labeled immature neurons sections are stained with the primary chicken anti-GFP antibody $(1: 1,000)$.

ii. Otherwise non-labeled immature neurons are stained with the goat antiDoublecortin antibody (1:200). Mouse anti-NeuN (1:200) might be used as additional marker to determine cell maturity. 
d. After incubation sections are transferred back to net carriers in 12 well plates, washed three times with TBS at RT.

e. After blocking in TBS++ for 30 min at RT sections are transferred again into $0.5 \mathrm{ml}$ Eppendorf Safelock tubes containing the diluted secondary antibody mix in TBS++. Sections in Eppendorf tubes in Falcons are incubated in secondary antibodies at $4{ }^{\circ} \mathrm{C}$ on a tube roller mixer for $2 \mathrm{~h}$.

i. Secondary antibodies are diluted 1:400: Donkey anti-chicken DyLight488, donkey anti-goat Alexa 647 or donkey anti-mouse Alexa 546.

ii. Hoechst $33342(1: 10,000)$ is used to counterstain DNA and added to the secondary antibody mix.

f. Finally, sections are placed back into net carriers in 12 well plates, washed three times for 15 min with TBS and additionally 4 times for 1 min in TBS at RT.

g. Sections are floated in $0.1 \mathrm{M}$ PB in a Petri dish, mounted on glass slides and embedded with $100 \mu \mathrm{l}$ Mowiol.

3. Confocal microscope pictures are taken with a 40x objective on a confocal microscope. Branching points and total dendrite length are measured using Amira Filament Editor Analysis (Visage Imaging).

C. Neuronal morphology analysis of mature hippocampal neurons

1. For analysis of neuronal morphology of mature CA or DG neurons PFA fixed brains are cut in two hemispheres and stained with the FD Rapid GolgiStain ${ }^{\mathrm{TM}}$ Kit.

a. Hemispheres are incubated in impregnation solution (A and $B$ ) for 2 weeks at RT in the dark.

b. After that tissue is transferred into solution $\mathrm{C}$ and stored for five days at $4{ }^{\circ} \mathrm{C}$ protected from light.

c. The tissue is cut in $100 \mu \mathrm{m}$ thick coronal sections floating in solution $\mathrm{C}$ with a Leica VT1200 vibratome and mounted on gelatine coated glass slides. To coat glass slides $1.5 \mathrm{~g}$ gelatine and $0.25 \mathrm{~g}$ chromium potassium sulfate are mixed with $500 \mathrm{ml}$ distilled water, a few crystals of bromthymol blue are added as preservative, heated up to 60 ${ }^{\circ} \mathrm{C}$ in order to dissolve gelatine and then glass slides are dipped into the solution and the lower part of the slide is cleaned with a tissue. Coated slides are dried overnight at RT.

d. Mounted slides are washed 2x for 2 min in Millipore water.

e. Sections are stained for $10 \mathrm{~min}$ in staining solution $(40 \mathrm{ml}$ solution $\mathrm{D}, 40 \mathrm{ml}$ solution $\mathrm{E}$ and $80 \mathrm{ml}$ Millipore water) at RT. 
f. Sections are washed $2 \times 4 \mathrm{~min}$ in Millipore water, once for $4 \mathrm{~min}$ in $50 \%$ ethanol (EtOH), once for $4 \mathrm{~min}$ in $75 \% \mathrm{EtOH}$, once for $4 \mathrm{~min}$ in $95 \% \mathrm{EtOH}$ and four times for 4 min in $100 \% \mathrm{EtOH}$ at RT.

g. Finally slices are washed three times for $4 \mathrm{~min}$ in xylene and embedded with Eukitt.

2. Neurons of the dentate gyrus and CA regions can be analysed with this method. Stacks can be recorded on a confocal microscope with a 40x objective. Branching points and total dendrite length are measured using Amira Filament Editor Analysis (Visage Imaging) (see Figure 2).

\section{$\underline{\text { Representative data }}$}

A

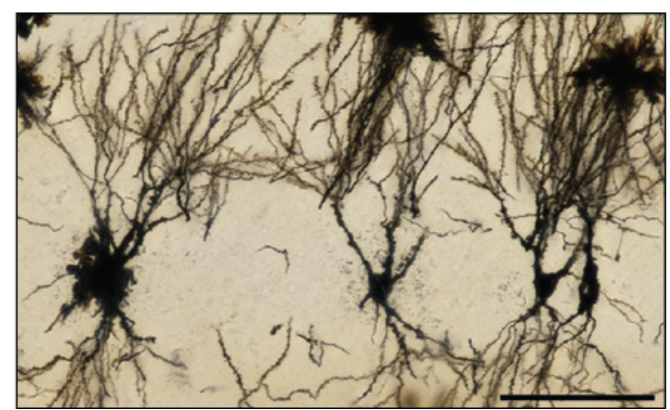

B



Figure 2. Light microscope (A) and confocal microscope picture (B) of Golgi stained neurons. Picture shown in B (left panel) was used for image analysis with Amira (right panel).

\section{$\underline{\text { Recipes }}$}

1. PBS (20x)

$\begin{array}{ll}\mathrm{NaCl} & 160 \mathrm{~g} / \mathrm{L} \\ \mathrm{Na}_{2} \mathrm{HPO}_{4} & 23 \mathrm{~g} / \mathrm{L} \\ \mathrm{NaH}_{2} \mathrm{PO}_{4} & 28.84 \mathrm{~g} / \mathrm{L} \\ \mathrm{KCl} & 4 \mathrm{~g} / \mathrm{L} \\ \mathrm{KH}_{2} \mathrm{PO}_{4} & 4 \mathrm{~g} / \mathrm{L}\end{array}$

Adjust $\mathrm{pH}$ to 7.4 with $\mathrm{HCl}$ and fill volume up to $1 \mathrm{~L}$ with $\mathrm{dH}_{2} \mathrm{O}$.

2. TBS (10x)

Trizma base $24.23 \mathrm{~g} / \mathrm{L}$ $\mathrm{NaCl}$ $80.06 \mathrm{~g} / \mathrm{L}$

Mix in $800 \mathrm{ml}$ ultra-pure water, adjust $\mathrm{pH}$ to 7.6 with pure $\mathrm{HCl}$ and fill up to $1 \mathrm{~L}$.

3. TBS ++ 
TBS $100 \mathrm{ml}$

Horse serum $\quad 3 \mathrm{ml}$

Triton X-100 $\quad 0.25 \mathrm{ml}$

4. $0.1 \mathrm{M}$ Phosphate buffer

$0.2 \mathrm{M}$ Monobasic Stock

$\mathrm{NaH}_{2} \mathrm{PO}_{4} \cdot \mathrm{H}_{2} \mathrm{O} \quad 13.9 \mathrm{~g} / 500 \mathrm{ml}$

$0.2 \mathrm{M}$ Dibasic Stock

$\mathrm{Na}_{2} \mathrm{HPO}_{4} \cdot 7 \mathrm{H}_{2} \mathrm{O}$

$53.65 \mathrm{~g} / \mathrm{L}$

Combine indicated amounts of $0.2 \mathrm{M}$ monobasic and $0.2 \mathrm{M}$ dibasic stock solutions and bring volume up to $600 \mathrm{ml}$.

\begin{tabular}{lll}
\hline $0.2 \mathrm{M}$ Monobasic Stock & $0.2 \mathrm{M}$ Dibasic Stock & $\mathrm{pH}$ \\
\hline $57 \mathrm{ml}$ & $243 \mathrm{ml}$ & 7.4 \\
\hline
\end{tabular}

5. Gelatine to coat glass slides

Gelatine

Chromium (III) potassium sulfate dodecahydrate

$0.25 \mathrm{~g}$

Add a few crystals of bromthymol blue as a preservative

Fill up to $500 \mathrm{ml}$ with $\mathrm{H}_{2} \mathrm{O}$ and heat up to $60{ }^{\circ} \mathrm{C}$ to dissolve gelatin.

6. Mowiol

1x PBS $\quad 40 \mathrm{ml}$

Mowiol $\quad 10 \mathrm{~g} \rightarrow$ stir for $24 \mathrm{~h}$

Add Glycerol $\quad 20 \mathrm{ml} \rightarrow$ stir for $24 \mathrm{~h}$

Centrifuge $15 \mathrm{~min}$ at $5,000 \mathrm{rpm}, \mathrm{RT}$

Aliquot and store at $-20^{\circ} \mathrm{C}$

\section{Acknowledgments}

This protocol is adapted from Seib et al. (2012).

\section{$\underline{\text { References }}$}

1. Seib, D. R., Corsini, N. S., Ellwanger, K., Plaas, C., Mateos, A., Pitzer, C., Niehrs, C., Celikel, T. and Martin-Villalba, A. (2013). Loss of Dickkopf-1 restores neurogenesis in old age and counteracts cognitive decline. Cell Stem Cell 12(2): 204-214. 